Research Article

\title{
Inhibition of PPAR $\gamma$ Gene Particle Downregulates the Differentiation of Rabbit Bone Marrow Mesenchymal Stem Cells into Adipocytes
}

\author{
Yi Dong, Long Chang, Long Hei, Sensen Yang, Wenxin Ma, and Huiqiang Ding \\ Department of Spinal Surgery, General Hospital of Ningxia Medical University, Yinchuan 750004, China \\ Correspondence should be addressed to Huiqiang Ding; dinghuiqiangnx@sina.com
}

Received 26 October 2021; Accepted 22 November 2021; Published 6 December 2021

Academic Editor: M Pallikonda Rajasekaran

Copyright ( $\odot 2021$ Yi Dong et al. This is an open access article distributed under the Creative Commons Attribution License, which permits unrestricted use, distribution, and reproduction in any medium, provided the original work is properly cited.

\begin{abstract}
This study aims to evaluate the effect of peroxisome proliferator-activated receptor (PPAR) $\gamma$ gene inhibition on the adipogenic differentiation of rabbit bone marrow mesenchymal stem cells (BMSCs). Primary BMSCs were isolated from rabbit bone marrow, cultured, and the markers of BMSCs on cell's surface were analyzed using flow cytometry. The experiment involved five groups, namely, control: untreated BMSCs; model: BMSCs treated with ethanol; empty siRNA: BMSCs treated with ethanol + empty siRNA; PPAR $\gamma$ : BMSCs treated with ethanol + PPAR $\gamma$ siRNA; and PPAR $\gamma$ inhibitor: BMSCs treated with ethanol + T0070907. RT-PCR and Western blotting were used to detect changes in the expression level of PPAR $\gamma$, PETALA2 (AP2), lipoprotein lipase (LPL), fatty acid transport protein (FATP) 1, and fatty acid transporter (FAT). Adipocyte count and triacylglycerol content of the model and the empty siRNA groups were considerably greater than the control group $(P<0.01)$. After the inhibition with PPAR $\gamma$ or T0070907, adipocyte count and triacylglycerol content of the PPAR $\gamma$ and T0070907 groups were significantly reduced $(P<0.01)$, with no statistically significantly difference than the control group $(P>0.05)$. The expression levels of PPAR $\gamma$ gene and protein in the model and empty siRNA groups were ominously enhanced than the control group $(P<0.01)$, and after inhibition with PPAR $\gamma$ or T0070907, the PPAR $\gamma$ gene or protein expression level of PPAR $\gamma$ and T0070907 groups significantly reduced $(P<0.01)$, with no statistically significance difference compared to the control group $(P>0.05)$. The expression levels of Ap2, LPL, FATP1, and FAT genes in the model and empty siRNA groups were considerably greater compared to the control group $(P<0.01)$. Inhibition with PPAR $\gamma$ or T0070907 in the PPAR $\gamma$ and T0070907 groups, respectively, lead to significantly reduced expression levels of adipogenic genes $(P<0.01)$, with no statistically significance difference compared to the control $(P>0.05)$. Inhibition of PPAR $\gamma$ gene downregulates the differentiation of BMSCs into adipocytes, indicating its putative role in the expression of adipogenic genes.
\end{abstract}

\section{Introduction}

The bone marrow stromal system is a network composed of stromal cells and extracellular matrix [1,2]. Bone marrow stromal cells contain pluripotent bone marrow mesenchymal stem cells with high proliferation rates and multilineage differentiation ability $[3,4]$. When exposed to alcohol, differentiation of bone marrow mesenchymal stem cells (BMSCs) into osteoblasts is significantly reduced, but their differentiation into adipocytes is greatly increased [5, 6]. Adipocyte count and triacylglycerol content in cells increase significantly with prolonged action time and concentration of alcohol, indicating that alcohol can induce BMSCs to differentiate into adipocytes in a dose dependent manner [7-10].

Alcohol also promotes the expression of adipogenic genes and induces the differentiation of pluripotent stromal stem cells into adipocytes in BMSCs at a certain stage of osteogenesis [11]. Increased lipid substance in the blood circulation leads to the accumulation of fat globules, which can eventually lead to avascular necrosis of femoral head (ANFH) through a variety of pathways. This study confirmed the role and molecular mechanism of peroxisome proliferator-activated receptor $\gamma$ inhibitor T0070907 for alcohol-induced differentiation of bone marrow stromal 
cells into adipocytes using cultured BMSCs harvested from normal rabbit femoral bone marrow.

\section{Experiment}

2.1. Isolation, Culture, and Identification of BMSCs Cells. A total of 20 six-week-old New Zealand white rabbits were sacrificed, and the long bones of limbs were removed under aseptic operation. The long bone marrow cavity was opened using rongeurs, and the medullary cavity was rinsed with the serum-free high-sugar DMEM medium to obtain bone marrow, and the suspension was centrifuged at $3000 \mathrm{rpm}$ for $3 \mathrm{~min}$. The supernatant was discarded, $4 \mathrm{~mL}$ of Dulbecco's modified Eagle's medium (DMEM) was added to the pellet, and the solution was pipetted repeatedly to yield a single cell suspension. Subsequently, the bone marrow cells were inoculated into culture flasks at a concentration of $6 \times 10^{6} / \mathrm{cm}^{2}$, followed by adding the complete DMEM culture medium, and the cells were cultured at $37^{\circ} \mathrm{C}$ in a $5 \% \mathrm{CO}_{2}$ incubator. The culture medium was changed every other day, and after 4 days, the supernatant was removed to obtain growing cells which were attached to the wall, i.e., the BMSCs. The morphology and growth of the cells were observed under an inverted microscope; after the primary cells were passaged, BMSCs at passage 2 were inoculated onto 6 -well culture plates, at a density of $1 \times 10^{4}$ cell per well, and marked as day 0 of the experiment. Approximately $1 \times 10^{6}$ cells at passage 5 were removed and resuspended in $100 \mu \mathrm{L}$ phosphate buffered saline (PBS), supplemented with respective antibodies and incubated for $30 \mathrm{~min}$ at room temperature. The harvested cells were then washed with PBS to remove unbound antibodies, resuspended in PBS, and detected using a flow cytometer. All animal experiments were approved by the Animal Ethics Committee of General Hospital of Ningxia Medical University.

2.2. Experimental Grouping. The experiment was performed in five groups, each with 3 culture wells. Control: BMSCs did not undergo any treatment. Model: BMSCs were treated with $0.09 \mathrm{~mol} / \mathrm{L}$ ethanol. Empty siRNA: BMSCs were treated with $0.09 \mathrm{~mol} / \mathrm{L}$ ethanol + empty siRNA. PPAR $\gamma$ : BMSCs were treated with $0.09 \mathrm{~mol} / \mathrm{L}$ ethanol + PPAR $\gamma$ siRNA. PPAR $\gamma$ inhibitor: BMSCs were treated with $0.09 \mathrm{~mol} / \mathrm{L}$ ethanol + T0070907 (Cayman Chemical, MI, USA).

2.3. RT-PCR. RT-PCR assay was performed to detect the expression level of PPAR $\gamma$, Ap2, LPL, FATP1, and FAT genes after ethanol-induced culture of BMSCs for 7 days and PPAR $\gamma$ in the femoral head tissue after 6 weeks of treatment using an ANFH model. Total RNA isolation reagent TRIzol was used to obtain the total RNA in the specimen tissue; $1 \mu \mathrm{L}$ of total RNA and $0.5 \mu \mathrm{L}$ AMV reverse transcriptase for reverse transcription; and $2.5 \mu \mathrm{L}$ template $\mathrm{cDNA}, 0.1 \mu \mathrm{L}$ polymerase Ex Taq $\mathrm{HS}$, and $0.1 \mu \mathrm{L}$ each of forward and reverse primers. The PCR parameters were as follows: initial denaturation at $94^{\circ} \mathrm{C}$ for $2 \mathrm{~min}, 35$ cycles of denaturation at $94^{\circ} \mathrm{C}$ for $40 \mathrm{~s}$, annealing at $50-65^{\circ} \mathrm{C}$ for $40 \mathrm{~s}$, and extension at $72^{\circ} \mathrm{C}$ for $1 \mathrm{~min}$, followed by final extension at $72^{\circ} \mathrm{C}$ for $5 \mathrm{~min}$. The PCR products were kept at $-20^{\circ} \mathrm{C}$ until further analysis. $\beta$-Actin was used as the internal reference, and all PCR amplifications were performed under the same conditions. Subsequently, $6 \mu \mathrm{L}$ of each PCR product was separated using $2 \%$ agarose gel electrophoresis at $120 \mathrm{~V}$, $100 \mathrm{~mA}$, for $30 \mathrm{~min}$. The gel was removed and stained in EB solution for about $5 \mathrm{~min}$ prior to image analysis. RT-PCR result interpretation: a clear band that matched the expected size of target fragment was considered a PCR positive result. Gray scan was performed, and Quantity One software (BioRad Inc) was used to analyze the bands of separated PCR products. The gray value ratio between target gene and internal reference ( $\beta$-actin) was used to calculate the relative expression of the mRNA product of target gene in the sample.

2.4. Western Blot. After 7 days of ethanol-induced culture for BMSCs, total cell protein was extracted. Protein elutes were separated using SDS-PAGE assay, in which the samples was separated on a $12 \%$ agarose gel at $80 \mathrm{~V}$ for an initial loading followed by $120 \mathrm{~V}$, until the tracking dye was $1 \mathrm{~cm}$ from the lower end of the gel. A PVDF membrane of appropriate size was soaked in methanol for $5 \mathrm{~min}$ and then soaked in transfer buffer (pH 8.3, $25 \mathrm{mmol} / \mathrm{L}$ Tris-HCl, $192 \mathrm{mmol} / \mathrm{L}$ glycine, 20\% methanol) for $10 \mathrm{~min}$; then, the separated protein samples on the PAGE gel were blotted onto the PVDF membrane using an electrotransfer setup of $100 \mathrm{~V}$ for $70 \mathrm{~min}$. The PVDF membrane was blocked with $5 \%$ bovine serum albumin/PBS solution at $4^{\circ} \mathrm{C}$ overnight. The corresponding primary antibodies including CD90-FITC, CD73-FITC, CD105-FITC, CD13FITC, CD45-FITC, and CD34-FITC, diluted at 1:2000, were added; then, the solution was allowed to stand at room temperature for $3 \mathrm{~min}$, and the membrane was washed in 0.05\% Tween 20 PBS solution for $10 \mathrm{~min}$ and repeated twice. Thereafter, the goat anti-mouse IgG secondary antibodies, diluted at 1:8000, were added, and the solution was allowed to stand at room temperature for $3 \mathrm{~h}$, and the membrane was washed in $0.05 \%$ Tween 20 PBS solution for $10 \mathrm{~min}$ and repeated twice. Electrochemiluminescence (ECL) reagent color development: the membrane was incubated in the equal proportion of solutions A and B of ECL kit for 1 min to develop chemiluminescence signal, which was detected and analyzed using the gel imaging system. The developed film was scanned and analyzed using Image J version 1.44 software, and the average density value (ADV) was determined, and its ratio to $\beta$-actin was used as the relative absorbance value of each group of products.

2.5. Statistical Analysis. The $t$-test, one-way, and chi-square test were used to determine statistical comparison between expression and fluorescence intensity, and SPSS (version 19.0) was used. All results were presented as bar charts with error bars describing the mean and standard error. $P<0.05$ was statistically significant.

\section{Results and Discussion}

3.1. Morphology and Flow Cytometry Analysis of BMSCs. Morphology of cultured rabbit BMSCs is shown in Figure 1. The surface expression of the antigens was measured by flow cytometric assessments, and the results were compared and 


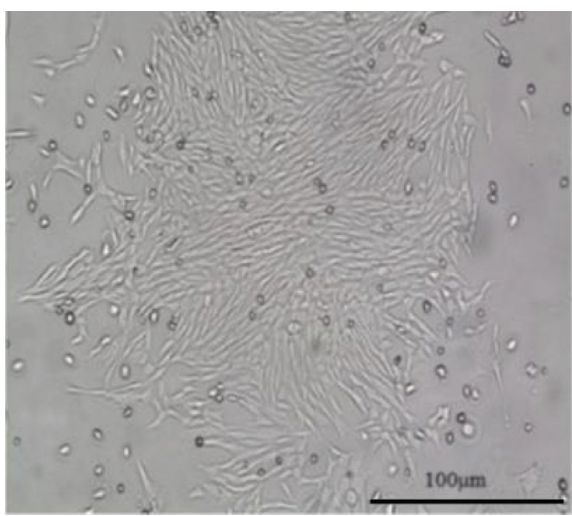

(a)

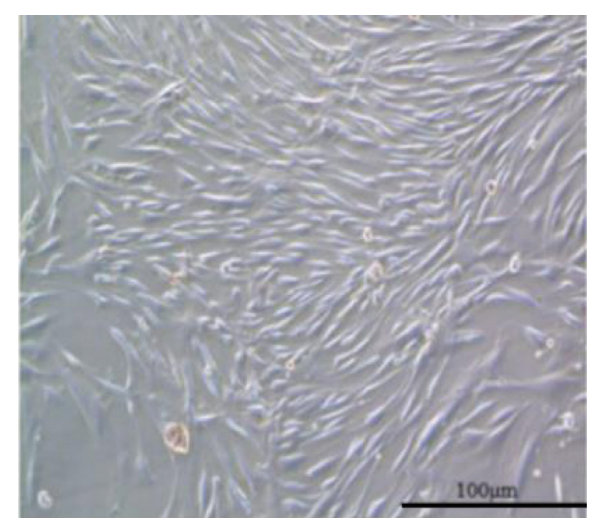

(b)

Figure 1: Morphological changes of rabbit BMSCs. (a) Three days and (b) five days after BMSCs culture, respectively.

evaluated. All surface antigens CD90 (89.05\%), CD105 (90.88\%), and CD73 (95.07\%) of BMSCs showed positive expression; CD13 (0.80\%), CD34 (1.06\%), and CD45 (1.30\%) showed no expression (Figure 2), which are consistent and support the previous reports.

\subsection{Comparison of Adipocyte Count, Triacylglycerol Content,} PPART Gene, and Protein Expression between Groups. The adipocytes are the permissive storage depots for triglycerides and also source secondary energy production. The adipocyte counts and triacylglycerol content of the model and the empty siRNA groups were considerably greater compared to the control group $(P<0.01)$. The adipocyte counts and triacylglycerol content of the PPAR $\gamma$ and T0070907 groups were significantly reduced $(P<0.01)$ after inhibition of PPAR $\gamma$ or adding T0070907, with no statistically substantial difference compared to the control group $(P>0.05)$. The expression levels of PPAR $\gamma$ gene and protein in the model and the empty siRNA groups were considerably greater compared to the control group $(P<0.01)$. Adding T0070907, the expression level of PPAR $\gamma$ gene or protein in the PPAR $\gamma$ and T0070907 groups significantly reduced $(P<0.01)$, with no statistically substantial difference compared to the control group $(P>0.05)$ (Figure 3$)$.

3.3. Comparison of Adipogenic Gene Transcription Levels between Groups. The gene transcription of adipogenic genes of various groups was assessed relatively and compared. The gene expression levels of Ap2, LPL, FATP1, and FAT of the model and empty siRNA groups were considerably greater compared to the control group $(P<0.01)$; after inhibition of PPAR $\gamma$ or adding T0070907, the expression levels of the adipogenic gene in the PPAR $\gamma$ and T0070907 groups were significantly reduced $(P<0.01)$, with no statistically substantial difference compared to the control $(P>0.05)$ (Figure 4$)$.

3.4. Discussion. BMSCs are the major composing cells with high self-replication ability and multilineage differentiation potential and can differentiate into variety of tissue developing cells. They not only could differentiate into chondrocytes, osteoblasts, adipocytes, muscle cells, and hematopoietic cells but also into nerve cells such as neurons and astrocytes $[12,13]$. Ideal markers for the identification of BMSCs have not been found. Therefore, characterization of the cells could only be based on the expression of protein markers on the surface of the cell at the later stage of attachment, such as positive CD44, CD13, CD105, CD59, CD166, and HLA-ABC or negative CD34, CD80, CD45, CD117, and HLA-DR $[14,15]$; but these surface antigens are not unique to BMSCs, which are identical to the characteristics of the surface antigen of mesothelial, epithelial, and endothelial cells. However, it is still a relatively reliable method to inversely identify the cells according to their phenotype, growth profile, and biological characteristics of cultured BMSCs [12-16]. The expression level of BMSCs surface antigen in this study is similar to the results reported in the literature, which consistently support the previous literature [17-21].

RNA interference (RNAi) offers the advantages of high efficiency and exquisite specificity. At present, RNAi-based gene therapy in experimental research is on genetic diseases. Research findings from both clinical and experimental studies have indicated that ANFH is attributed to pathophysiological changes due to the accumulation of fat in the bone marrow and abnormal fat metabolism [22, 23]. In vitro experiments have confirmed that ethanol can upregulate the expression of PPAR $\gamma$ mRNA in BMSCs and accelerate the differentiation of BMSCs into adipocytes, which ultimately leads to the proliferation and accumulation of a large number of adipocytes. The bone cells in the femoral head could die due to lipid deposition and fatty degeneration $[23,24]$. Studies have reported that PPAR $\gamma$ may be an important target gene that causes ANFH, and by blocking its expression, ethanol-induced adipocyte differentiation of BMSCs could be aberrated, and preventing the formation of ethanolic ANFH has significant application prospects [25-27]. This study showed that siRNA and T0070907 treatment achieved the same therapeutic effect by inhibiting the expression of PPAR $\gamma$ gene or protein of BMSCs, thereby, downregulating the differentiation of BMSCs into adipocytes. 


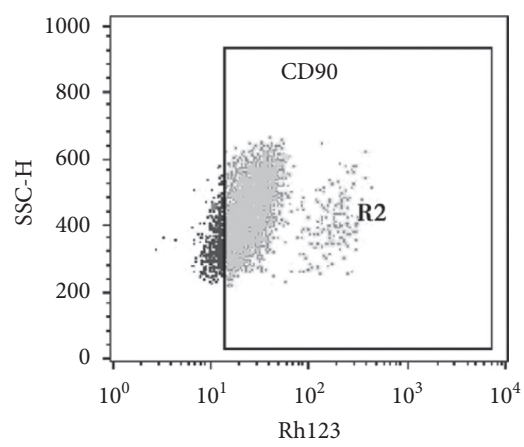

(a)

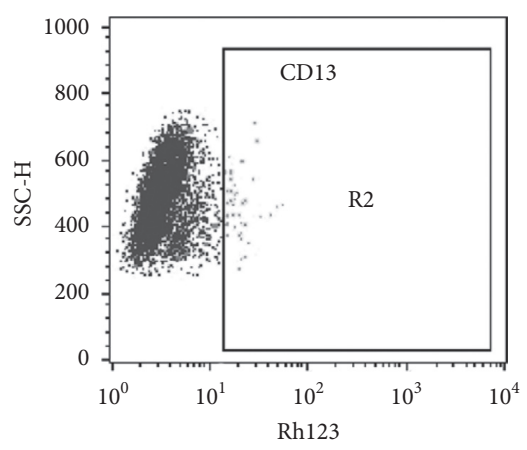

(d)

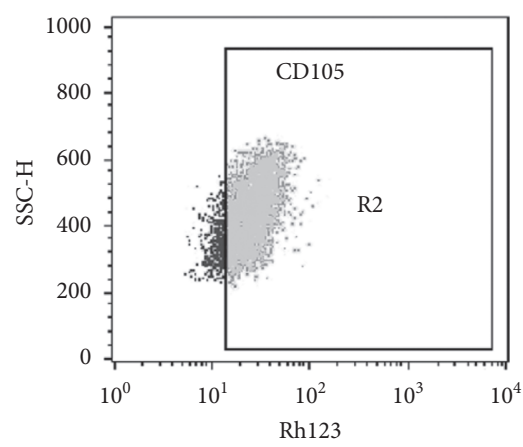

(b)

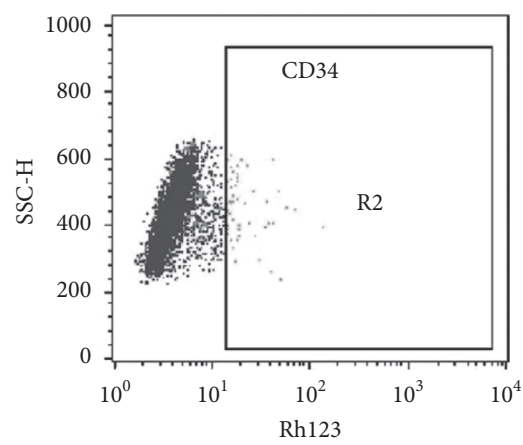

(e)

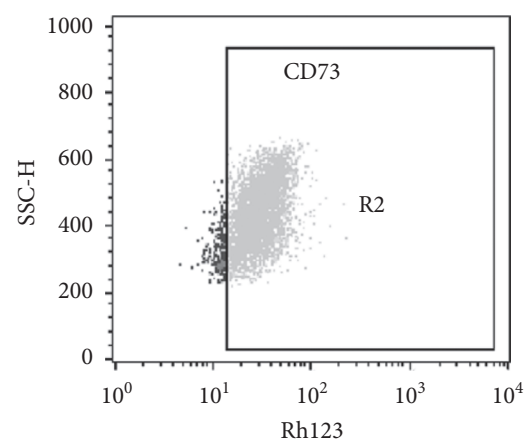

(c)

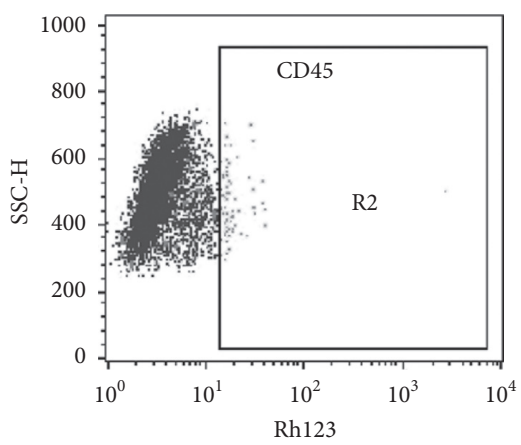

(f)

Figure 2: Surface markers of rabbit BMSCs by flow cytometry analysis. Expressions of surface antigens (a) CD90, (b) CD105, and (c) CD73 of BMSCs are positive, but (d) CD13, (e) CD34, and (f) CD45 of BMSCs are not expressed.

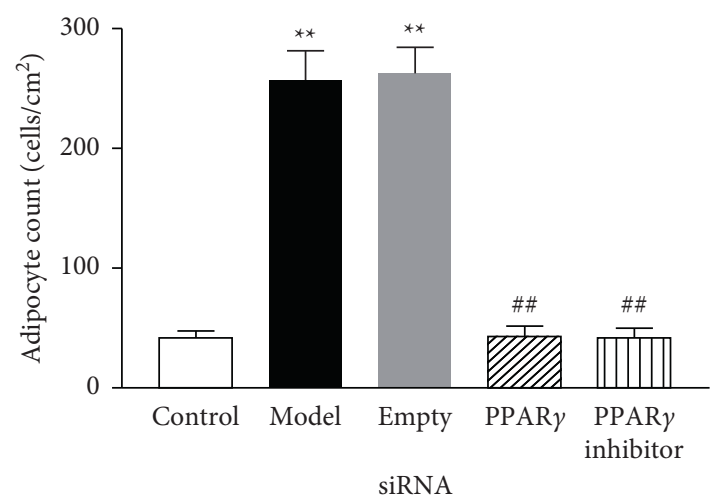

(a)

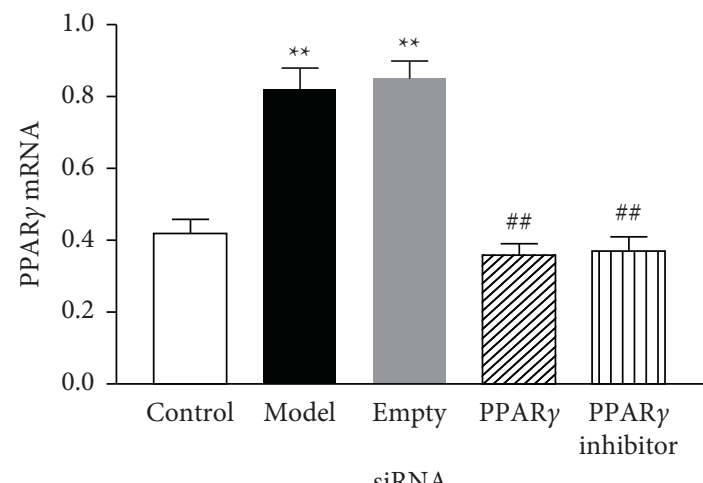

(c)

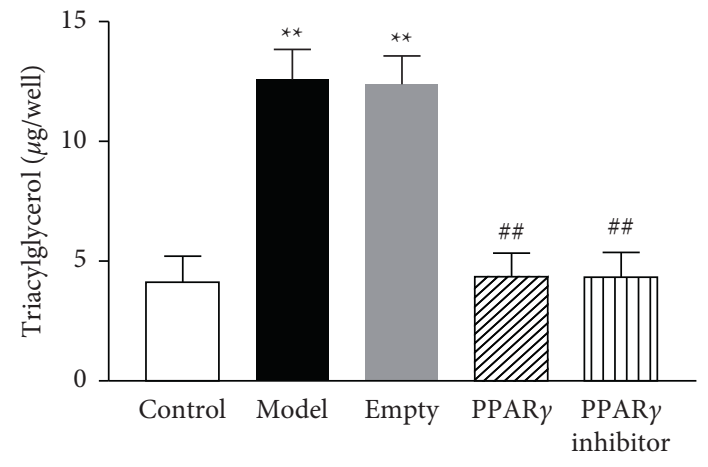

(b)

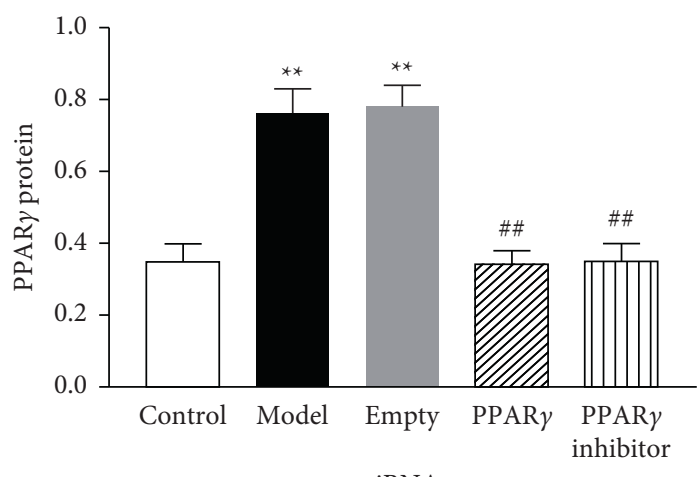

(d)

FIGURE 3: Comparison of (a) adipocyte count, (b) triacylglycerol content, (c) PPAR $\gamma$ gene, and (d) PPAR $\gamma$ protein expression between groups $(n=3)$. Compared to the control group, ${ }^{*} P<0.01$. Compared to the model and empty siRNA groups, $P<0.01$. 


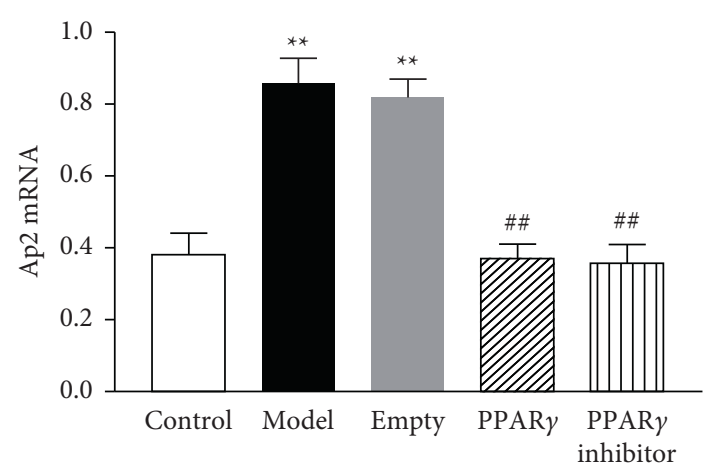

siRNA

(a)

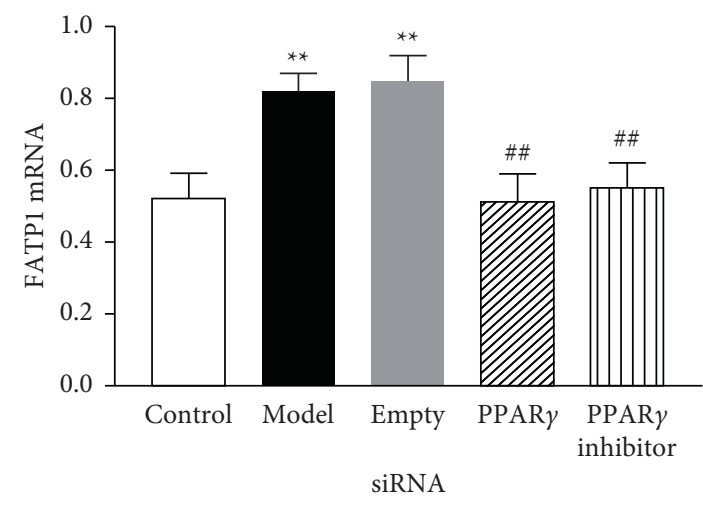

(c)

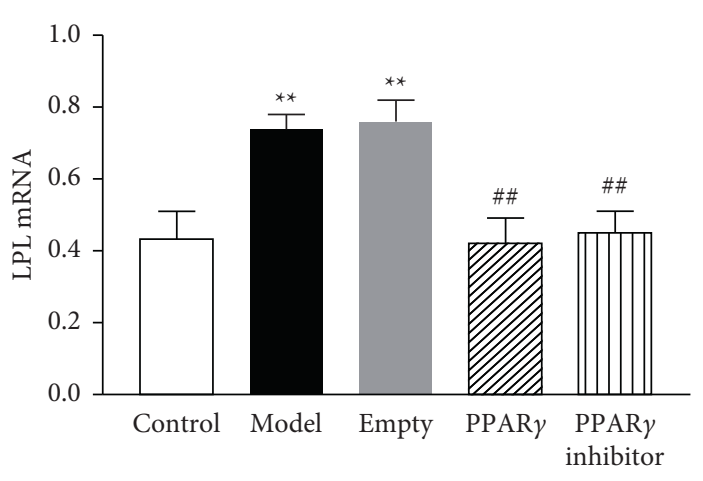

siRNA

(b)

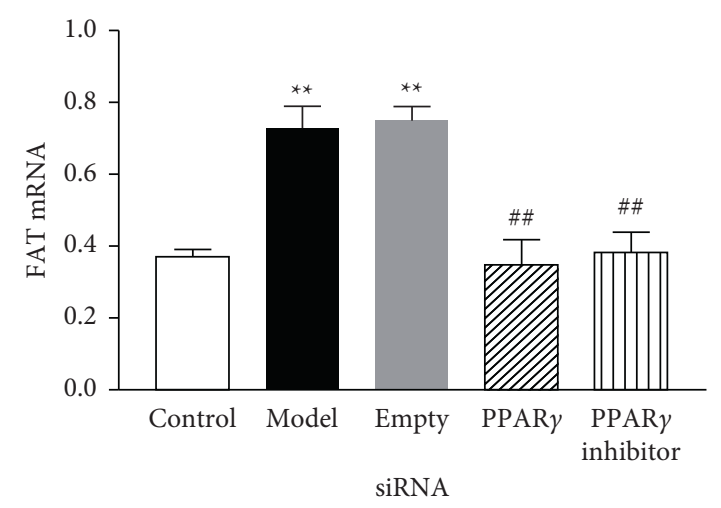

(d)

Figure 4: Comparison of transcription levels of adipogenic genes (a) Ap2, (b) LPL, (c) FATP1, and (d) FAT among groups ( $n=3$ ). Compared to the control group, ${ }^{*} P<0.01$. Compared to the model and empty siRNA groups, $P<0.01$.

Ap2 is an essential marker for the formation of mature adipocytes. It is located downstream of PPAR $\gamma$. It is mainly used as a target gene for fat storage and fat catabolism. Studies have shown that the expression of PPAR $\gamma$ and Ap2 mRNA in the adipose tissue of obese rats is significantly increased [28], which significantly enhanced fat synthesis. This study demonstrated that interfering the expression of the PPAR $\gamma$ gene or T0070907 treatment can significantly reduce the expression level of downstream Ap2 gene, which is consistent with the study. LPL is a key enzyme that hydrolyzes triacylglycerol into chylomicrons and very low-density lipoproteins. The lipoprotein metabolism is regulated through the catalytic activity of enzymes, thereby, achieving the effect of regulating blood lipids. Blood lipids irregularity can lead to severely head tackled complications. Studies have shown that LPL is an important lipo-regulating enzyme downstream of PPAR $\gamma$. When the PPAR $\gamma$ activity of the body decreases, the amount of LPL secretion and enzyme activity of the body significantly decreased [29]. FAT, a lipotransferase, was first isolated from mouse adipose tissue. It plays a vital role in transporting and regulating the absorption of fatty acids across the skeletal muscle cell membrane [30]. FATP1 has a binding site for the PPAR $\gamma$ target gene. In adipocytes, PPAR $\gamma$ upregulates the expression of FATP1, which coregulates the transmembrane transport of fatty acids with protein factor, FAT [31-33]. The fallouts of the current research work reveal that the transcription of adipogenic genes could be reduced by inhibiting the expression of the PPAR $\gamma$ gene, thereby, achieving the promising therapeutic effect.

\section{Conclusion}

Inhibition of PPAR $\gamma$ gene downregulates the differentiation of BMSCs into adipocytes, indicating its putative role in the expression of adipogenic genes. High lipid contents in the bloodstream cause fat globules to form, which can contribute to avascular necrosis of the femoral head (ANFH) via a range of mechanisms. Using cultured BMSCs taken from normal rabbit femoral bone marrow, this work verified the function and molecular mechanism of the peroxisome proliferator-activated receptor inhibitor T0070907 in alcohol-induced differentiation of bone marrow stromal cells into adipocytes. The reduction in the transcription of adipogenic genes may be helpful in developing a standard therapeutic option.

\section{Data Availability}

The datasets used and/or analyzed during the current study are available from the corresponding author upon request.

\section{Conflicts of Interest}

The authors declare that they have no conflicts of interest. 


\section{Authors' Contributions}

Yi Dong and Long Chang contributed equally to this article.

\section{Acknowledgments}

This work was funded by the Natural Science Foundation of Ningxia (2019AAC03207).

\section{References}

[1] O. W. Bastian, M. Croes, J. Alblas, L. Koenderman, L. P. H. Leenen, and T. J. Blokhuis, "Neutrophils inhibit synthesis of mineralized extracellular matrix by human bone marrow-derived stromal cells in vitro," Frontiers in Immunology, vol. 9, no. 1, p. 945, 2018.

[2] S. Gronthos, P. J. Simmons, S. E. Graves, and P. G. Robey, "Integrin-mediated interactions between human bone marrow stromal precursor cells and the extracellular matrix," Bone, vol. 28, no. 2, pp. 174-181, 2001.

[3] H. Li, R. Ghazanfari, D. Zacharaki, H. C. Lim, and S. Scheding, "Isolation and characterization of primary bone marrow mesenchymal stromal cells," Annals of the New York Academy of Sciences, vol. 1370, no. 1, pp. 109-118, 2016.

[4] J. L. Spees, R. H. Lee, and C. A. Gregory, "Mechanisms of mesenchymal stem/stromal cell function," Stem Cell Research \& Therapy, vol. 125, 2016.

[5] C. Wang, H. Meng, X. Wang, C. Zhao, J. Peng, and Y. Wang, "Differentiation of bone marrow mesenchymal stem cells in osteoblasts and adipocytes and its role in treatment of osteoporosis," Medical Science Monitor, vol. 22, pp. 226-233, 2016.

[6] Q. Chen, P. Shou, C. Zheng et al., "Fate decision of mesenchymal stem cells: adipocytes or osteoblasts?" Cell Death \& Differentiation, vol. 23, no. 7, pp. 1128-1139, 2016.

[7] H. Zhao, X. Liu, L. Yu et al., "Comprehensive landscape of epigenetic-dysregulated lncRNAs reveals a profound role of enhancers in carcinogenesis in BC subtypes," Molecular Therapy - Nucleic Acids, vol. 23, pp. 667-681, 2021.

[8] D. Jiang, F.-X. Chen, H. Zhou et al., "Bioenergetic crosstalk between mesenchymal stem cells and various ocular cells through the intercellular trafficking of mitochondria," Theranostics, vol. 10, no. 16, pp. 7260-7272, 2020.

[9] Y. Liu, J. Zhang, Y. Sun, X. Zhou, K. Yuan, and Z. Cui, "Study on the function of self-polymerizing peptide nanofiber material combined with nerve growth factor-mediated RNA repair for nerve injury treatment in rabbits with the osteofascial compartment syndrome," Materials Express, vol. 10, no. 7, pp. 1149-1154, 2020.

[10] J. H. Wu, A. R. Thoreson, A. Gingery et al., "The revitalisation of flexor tendon allografts with bone marrow stromal cells and mechanical stimulation:An ex vivo model revitalising flexor tendon allografts," Bone \& Joint Research, vol. 6, no. 3, pp. 179-185, 2017.

[11] C. Vitale-Brovarone, G. Ciapetti, E. Leonardi et al., "Resorbable glass-ceramic phosphate-based scaffolds for bone tissue engineering: synthesis, properties, andIn vitroEffects on human marrow stromal cells," Journal of Biomaterials Applications, vol. 26, no. 4, pp. 465-489, 2011.

[12] X. Ma, N. Lin, Y. Kang, L. Li, and W. Zheng, "Screening and identification of highly specific MAbs for discovering novel biomarkers of bone marrow stromal cells," Monoclonal Antibodies in Immunodiagnosis and Immunotherapy, vol. 35, no. 4, pp. 199-211, 2016.
[13] K. Pekovits, J. M. Kröpfl, I. Stelzer, M. Payer, H. Hutter, and G. Dohr, "Human mesenchymal progenitor cells derived from alveolar bone and human bone marrow stromal cells: a comparative study," Histochemistry and Cell Biology, vol. 140, no. 6, pp. 611-621, 2013.

[14] H.-T. Liao and C. T. Chen, "Osteogenic potential: comparison between bone marrow and adipose-derived mesenchymal stem cells," World Journal of Stem Cells, vol. 6, no. 3, pp. 288-295, 2014.

[15] A. García-García, C. L. de Castillejo, and S. Méndez-Ferrer, "BMSCs and hematopoiesis," Immunology Letters, vol. 168, no. 2, pp. 129-135, 2015.

[16] P. Chen, H. Huang, J. Wu et al., "Bone marrow stromal cells protect acute myeloid leukemia cells from anti-CD44 therapy partly through regulating PI3K/Akt-p27 Kip1 axis," Molecular Carcinogenesis, vol. 54, no. 12, pp. 1678-1685, 2015.

[17] L. He, T. He, J. Xing et al., "Bone marrow mesenchymal stem cell-derived exosomes protect cartilage damage and relieve knee osteoarthritis pain in a rat model of osteoarthritis," Stem Cell Research \& Therapy, vol. 276, 2020.

[18] D. Pan, X. X. Xia, H. Zhou et al., "Coco enhances the efficiency of photoreceptor precursor differentiation in early human embryonic stem cell-derived retinal organoids," Stem Cell Research \& Therapy, vol. 11, no. 1, p. 366, 2020.

[19] Q. Zou, P. Xing, L. Wei, and B. Liu, "Gene2vec: gene subsequence embedding for prediction of mammalian N6methyladenosine sites from mRNA," RNA, vol. 25, no. 2, pp. 205-218, 2019.

[20] Y. C. Cui, Y. S. Qiu, Q. Wu et al., "Hypoxic-mediated oxidative stress condition and hydroxyapatite-inducing osteogenic differentiation of human mesenchymal stem cells: a mathematical modeling study," Journal of Biomedical Nanotechnology, vol. 16, no. 6, pp. 910-921, 2020.

[21] G. Shang, Y. Wang, Y. Xu et al., "Long non-coding RNA TCONS_00041960 enhances osteogenesis and inhibits adipogenesis of rat bone marrow mesenchymal stem cell by targeting miR-204-5p and miR-125a-3p," Journal of Cellular Physiology, vol. 233, no. 8, pp. 6041-6051, 2018.

[22] A. K. Gatta, R. Chandrashekhar, N. Udupa, M. S. Reddy, S. Mutalik, and V. R. Josyula, "Strategic design of dicer substrate sirna to mitigate the resistance mediated by ABCC1 in doxorubicin-resistant breast cancer," Indian Journal of Pharmaceutical Sciences, vol. 82, no. 2, pp. 329-340, 2020.

[23] S. D. Gupta, C. V. S. Subrahmanyam, N. L. Gowrishankar, and N. M. Raghavendra, "Conserved water molecule-dependent docking strategy and atom-based 3D QSAR studies to design heat shock protein 90 inhibitors," Indian Journal of Pharmaceutical Sciences, vol. 82, no. 2, pp. 341-355, 2020.

[24] S. Maria, M. H. Swanson, L. T. Enderby et al., "Melatoninmicronutrients Osteopenia treatment study (MOTS): a translational study assessing melatonin, strontium (citrate), vitamin D3 and vitamin K2 (MK7) on bone density, bone marker turnover and health related quality of life in postmenopausal osteopenic women following a one-year doubleblind RCT and on osteoblast-osteoclast co-cultures," Aging, vol. 9, no. 1, pp. 256-285, 2017.

[25] Q. Zhao, Y. Lu, H. Yu, and X. Gan, "Low magnitude high frequency vibration promotes adipogenic differentiation of bone marrow stem cells via P38 MAPK signal," PLoS One, vol. 12, no. 3, Article ID e0172954, 2017.

[26] T. Wang, S. Teng, Y. Zhang, F. Wang, H. Ding, and L. Guo, "Role of mesenchymal stem cells on differentiation in steroidinduced avascular necrosis of the femoral head," Experimental and Therapeutic Medicine, vol. 13, no. 2, pp. 669-675, 2017. 
[27] S. Halim, R. S. Prasad, and M. Dhobi, "Quality control standardization and comparative anthelmintic activity of different extracts from evolvulus alsinoides L," Indian Journal of Pharmaceutical Sciences, vol. 82, no. 2, p. 356, 2020.

[28] Y. Gao, X. Guo, S. Wang et al., "Perfluorooctane sulfonate enhances mRNA expression of PPAR $\gamma$ and ap2 in human mesenchymal stem cells monitored by long-retained intracellular nanosensor," Environmental Pollution, vol. 263, Article ID e114571, 2020.

[29] V. Frodermann, J. van Duijn, M. van Pel et al., "Mesenchymal stem cells reduce murine atherosclerosis development," Scientific Reports, vol. 5, Article ID e15559, 2015.

[30] P. Hindle, N. Khan, L. Biant, and B. Péault, "The infrapatellar fat pad as a source of perivascular stem cells with increased chondrogenic potential for regenerative medicine," Stem Cells Translational Medicine, vol. 6, no. 1, pp. 77-87, 2017.

[31] Q. Jiang, S. Jin, Y. Jiang et al., “Alzheimer'd variants with the genome-wide significance are significantly enriched in immune pathways and active in immune cells," Molecular Neurobiology, vol. 54, no. 1, pp. 594-600, 2017.

[32] M. Liu, Y. Hu, and Y. Feng, "Evaluation of low molecular weight polyethylenimine-introduced chitosan for gene delivery to mesenchymal stem cells," Materials Express, vol. 10, no. 7, pp. 1170-1176, 2020.

[33] W. Zhang, Q. Sun, W. Zhong, X. Sun, and Z. Zhou, "Hepatic peroxisome proliferator-activated receptor gamma signaling contributes to alcohol-induced hepatic steatosis and inflammation in mice," Alcoholism: Clinical and Experimental Research, vol. 40, no. 5, pp. 988-999, 2016. 